\title{
O EFEITO DA ÉPOCA DE IRRIGAÇÃO E DE PARCELAMENTOS DE ADUBAÇÃO SOBRE A PRODUTIVIDADE DO CAFEEIRO EM TRÊS SAFRAS CONSECUTIVAS ${ }^{1}$
}

\author{
Irrigation seasons and splitting fertilizer effects on coffee plant productivity \\ of three crops consecutive
}

\author{
Gilberto Coelho ${ }^{2}$, Antônio Marciano da Silva ${ }^{3}$
}

\section{RESUMO}

Os benefícios da irrigação sobre a produtividade do cafeeiro estão relatados em diversos trabalhos. Entretanto, resta indagar sobre o efeito da irrigação no comportamento dessa cultura em safras consecutivas. Com o presente trabalho objetivou-se avaliar o efeito de diferentes épocas de irrigação e de parcelamentos de adubação sobre o ciclo bienal de produtividade do cafeeiro. Usou-se um experimento em faixas, em que nas parcelas foram testados diferentes parcelamentos de adubação: parcela 1 (P1) recebeu 12 aplicações de fertilizantes de forma manual, parcelas 2, 3 e 4 (P2, P3 e P4) receberam, respectivamente, 12, 24 e 36 aplicações de fertilizantes via água de irrigação. Nas faixas (subparcelas), foram testadas 3 épocas de irrigação, 01/06 a 30/09 (subparcela A), 15/07 a 30/09 (subparcela B), 01/09 a 30/09 (subparcela C) e um tratamento-testemunha sem irrigação (subparcela D), com 3 repetições (Blocos). Os resultados de produtividade de café de pano, de chão e produtividade total expressos em $\mathrm{kg} \mathrm{ha}^{-1}$, foram submetidos à análise de variância e ao teste de comparação de médias, quando este se fez necessário. Pela análise de variância, possibilitou-se detectar efeito significativo do parcelamento de adubação apenas para a produtividade de café de pano e, desta forma, P1 proporcionou o melhor resultado, $3120 \mathrm{~kg} \mathrm{ha}^{1}$; e as épocas de irrigação mostraram efeito significativo para os três parâmetros estudados. A única interação significativa estatisticamente foi entre safras e épocas de irrigação, o que mostra que a irrigação não elimina o ciclo bienal de produtividade do cafeeiro. Recomenda-se irrigar a partir de 01/06, pois esse tratamento apresentou melhores resultados em duas das três safras estudadas e também o menor coeficiente de variação da produtividade.

Termos para indexação: Irrigação, fertirrigação, produtividade, ciclo bienal, coffea arábica.

\section{ABSTRACT}

The positive effects of irrigation on coffee crop productivity are reported in several scientific works. However, it is necessary to investigate the irrigation effect on coffee plant behavior, in consecutive harvests. Therefore, the present study purposes to evaluate the irrigation seasons and splitting fertilizer effects on coffee plant biennial productivity cycle. An experiment was carried out in split plots, testing different fertilizer numbers applications: plot 1 (P1) has received 12 manual fertilizers applications; plots 2, 3 and 4 (P2, P3 and P4) have received, respectively, 12, 24 and 36 fertilizers applications by irrigation water. In subplots, 3 irrigations seasons were tested, working with 3 replications (blocks): 01/jun to 30/set (subplot A), 15/jul to 30/set (subplot B), 01/set to 30/set (subplot C) and a treatment for testifying without irrigation (subplot D). Cloth and ground coffee productivity and total productivity, in $\mathrm{kg} \mathrm{ha}^{-1}$, were evaluated by ANOVA and mean tests. Significant effects of fertilizer applications, on cloth coffee productivity, were verified by ANOVA, with P1 split plot has provided the best productivity (3120 $\mathrm{kg} \mathrm{ha}^{-1}$ ). Irrigation seasons have showed significant effects on three parameters studied. Significant statistical interaction was verified only among crops and irrigation seasons. Those results demonstrate that irrigation does not have eliminated the coffee plant biennial productivity cycle. It is recommended to start irrigation from $01 /$ jun, because this treatment has produced better results than others, in two of the three crops studied, besides the smallest coefficient of variation concerning productivity.

Index terms: irrigation, fertirrigation, productivity, biennial cycle, coffea Arabica.

\section{(Recebido para publicação em 24 de julho de 2002 e aprovado em 21 de fevereiro de 2005)}

\section{INTRODUÇÃO}

O Brasil é o maior produtor e exportador mundial de café, sendo responsável por cerca de $25 \%$ da produção mundial e cerca de $17 \%$ das exportações mundiais. Além disso, é o segundo mercado consumidor, depois dos Estados Unidos da América. (ANUÁRIO..., 2001).
As áreas produtoras de café no Brasil estão distribuídas principalmente na região centro-sul, nos Estados de Minas Gerais, São Paulo, Espírito Santo e Paraná. O sul de Minas Gerais, além de produzir 25\% do café brasileiro, é caracterizado pela produção de cafés de excelente qualidade, devido às suas condições de clima e solo favoráveis ao desenvolvimento da cultura.

1. Parte da dissertação de mestrado do $1^{\circ}$ autor.

2. Engenheiro Agrícola - Doutorando em Engenharia Agrícola - Irrigação e Drenagem - Pesquisador/Bolsista do CNP\&D/café - Dr. Octaviano de Carvalho, 70 - 37.200-000 - Lavras/MG - coelho@ufla.br

3. Professor Titular do Departamento de Engenharia da Universidade Federal de Lavras/UFLA - Pesquisador Bolsista CNPq - Caixa Postal 3037 37.200-000 - Lavras,MG. 
Os produtores têm adotado novas tecnologias de condução e manejo da lavoura, como o adensamento, a mecanização, inclusive da colheita, e a irrigação/fertirrigação, a fim de aumentar a produtividade e, conseqüentemente, a margem de lucro.

A irrigação do cafeeiro surgiu com o avanço dessa cultura para as regiões consideradas marginais ao seu cultivo quanto às suas necessidades hídricas, como, por exemplo, o cerrado mineiro e o oeste baiano. Nessas regiões, a cafeicultura só é viável quando irrigada e, dessa maneira, vale ressaltar, têm-se alcançado elevadas produtividades, com um produto de alta qualidade.

Segundo Santinato et al. (1996), sem a prática da irrigação, nas áreas onde o déficit hídrico chega a comprometer a produção, o País deixaria de produzir de 2 a 2,5 milhões de sacas beneficiadas por ano.

A utilização da fertirrigação oferece inúmeras vantagens em comparação com o método convencional de aplicação de fertilizantes. Entre elas, pode-se destacar a não-compactação do solo e o fim de injúrias mecânicas nas plantas, causadas pela entrada de equipamentos pesados nas áreas de cultivos para promover a adubação pelos métodos tradicionais; menor quantidade de equipamento exigido e menor gasto de energia; a dosagem de nutrientes pode ser mais cuidadosamente regulada, monitorada, distribuída e parcelada no perfil do solo, conforme as necessidades da cultura ao longo de seu ciclo fenológico.

A irrigação do cafeeiro tem proporcionado um avanço tecnológico considerável nos últimos 8 a 10 anos. Estima-se que a cafeicultura irrigada por diferentes sistemas atinja cerca de 100 mil hectares, entre lavouras já instaladas em regiões tradicionais, como os cerrados e nas novas fronteiras, como Goiás, Mato Grosso e Bahia. Quanto aos sistemas utilizados, verificouse evolução, partindo dos sistemas de irrigação por superfície (sulcos), em 1946, para a aspersão convencional, seguido pelo canhão e o autopropelido e, finalmente, tubos perfurados a laser (ou mangueira plástica perfurada, MPP), o pivô central e o gotejamento (SANTINATO, 2001).

Alguns questionamentos, que não foram ainda devidamente esclarecidos, dizem respeito à interação entre a irrigação e o período em que os pesquisadores dizem que a cultura deve passar por um período de déficit hídrico para a uniformização de florada, além do comportamento bienal da cultura quanto à sua produtividade.

Estudos de balanços hídricos nas diferentes regiões cafeeiras do Brasil e do mundo indicam que o cafeeiro arábica suporta até $150 \mathrm{~mm} /$ ano de déficit hídrico, especialmente se esse período não se prolongar até o mês de setembro e se as condições de solo (textura e profundidade) forem adequadas (solos argilosos e profundos). Da mesma forma, para o cafeeiro robusta, a deficiência hídrica não deve exceder a 200 mm/ano (SANTINATO et al., 1996).

O Instituto Brasileiro de Café (IBC), em trabalhos realizados em regiões com déficit hídrico limitante ao cafeeiro arábica, demonstrou a importância da irrigação para viabilização técnico-econômica da cultura, com aumentos médios de produtividade da ordem de 20 a 30 sacas de café beneficiado por hectare (SANTINATO et al., 1996).

Sorice (1999), em Lavras, MG, irrigando por gotejamento com diferentes parcelamentos de adubação via água e épocas de início de irrigação, verificou efeito significativo, tanto do parcelamento da adubação, como da época de início de irrigação, que propiciaram aumentos da ordem de $95 \%$ a $120 \%$, quando comparados com a testemunha.

Fernandes et al. (2000) descreveram uma produtividade no ano agrícola 1997/98 igual a 45,7 sc ha ${ }^{-1} \mathrm{em}$ trabalho conduzido com a variedade Catuaí com 8 anos de idade, na região de Bonfinópolis-MG e irrigando, o ano todo, com gotejadores autocompensantes da marca Katif, com vazão de $4 \mathrm{~L} / \mathrm{h}$.

Antunes et al. (2000), nos anos agrícolas 1998/99 e 1999/2000, usaram tubogotejador labirinto, da marca Queen Gil, com vazão média de $1 \mathrm{~L} / \mathrm{h}$ e emissores espaçados de $30 \mathrm{~cm}$, irrigando durante $\mathrm{o}$ ano todo e fertirrigando a variedade Catuaí (espaçadas de 2,5 x 1,0 m) com 8 anos, no município de Rio Preto-MG, região do Campo das Vertentes, obtiveram os seguintes resultados: 43,37 sc ha ${ }^{-1}$ e 78,1 sc ha ${ }^{-1}$ para os anos agrícolas 1998/99 e 1999/2000, respectivamente.

Faria et al. (2001), trabalhando na região de Lavras - MG (safra 1999/2000), com a cultivar Acaiá (plantada no espaçamento de 3,0 x 0,6 m) e irrigando o ano todo, alcançou uma produtividade de 84,95 sc ha-1. Já Soares et al. (2001), em trabalho desenvolvido em Viçosa, na Zona da Mata do Estado de Minas Gerais, com a variedade Catuaí (safra 1999/2000) de 8 anos de idade e plantada no espaçamento de $3,0 \times 1,0 \mathrm{~m}$, irrigando e fertirrigando com Hidran-plus na fórmula 19-04-19 e 9 aplicações anuais, conseguiram uma produtividade igual a 88,0 sc ha ${ }^{-1}$. Em relação ao ciclo bienal do cafeeiro, Weill et al. (2000) afirmaram que as produtividades de café apresentaram acentuado ciclo bienal, para trabalhos conduzidos com a variedade Mundo Novo, no período de 1972 a 1976.

Embora existam vários estudos relacionados à adoção da irrigação para a cafeicultura, há muita 
controvérsia sobre seus verdadeiros efeitos, particularmente para as chamadas regiões aptas quanto ao regime hídrico.

Como trabalho objetivou-se avaliar os efeitos de diferentes épocas da irrigação e de parcelamentos da adubação na produtividade da cultura do cafeeiro Catuaí, em três safras (1997/1998, 1998/1999 e 1999/2000).

\section{MATERIAL E MÉTODOS}

\section{A cultura e o delineamento experimental}

O experimento foi conduzido numa cultura de café ‘Catuaí Vermelho’ (IAC - 144). No início do experimento, a cultura tinha 11 anos de idade, espaçamento de 3,5 m x 0,8 m em uma área útil de $2.240 \mathrm{~m} 2$, localizada em Lavras (MG), a uma altitude de 910 metros, latitude sul de $21^{\circ} 14^{\prime}$ e longitude oeste de $45^{\circ} 00^{\prime}$.

A área experimental foi distribuída em três blocos, divididos em quatro parcelas casualizadas, as quais foram subdivididas em quatro subparcelas com oito plantas, sem casualização. Nas parcelas, foram analisados os efeitos do número de parcelamentos de $\mathrm{N}, \mathrm{P}$ e K aplicados manualmente e via água de irrigação (fertirrigação), sendo:

- $\quad$ parcela 1 (P1): adubação convencional (manual) com 12 parcelamentos;

- $\quad$ parcela 2 (P2): adubação via água de irrigação com 12 parcelamentos;

- $\quad$ parcela 3 (P3): adubação via água de irrigação com 24 parcelamentos;

- $\quad$ parcela 4 (P4): adubação via água de irrigação com 36 parcelamentos.

A aplicação de fertilizantes foi iniciada em outubro e encerrada em março. Nas subparcelas, avaliou-se o efeito das diferentes épocas de irrigação, sendo:

- $\quad$ subparcela A: irrigação realizada de 01/06 a 30/09;

- $\quad$ subparcela B: irrigação realizada de 15/07 a 30/09;

- $\quad$ subparcela C: irrigação realizada de 01/09 a 30/09;

- $\quad$ subparcela D: não-irrigada e adubação manual parcelada em quatro vezes, utilizando a mesma fonte de nutrientes da fertirrigação.

Esse arranjo resultou num delineamento experimental com blocos casualizados com parcelas subdivididas em faixas.

\section{Sistema de irrigação e manejo do experimento}

O sistema de irrigação constou de tubogotejadores modelo QUEEN GIL, o qual apresenta uma vazão de $0,4 \mathrm{~L} / \mathrm{h}$ por emissor a uma pressão de $7 \mathrm{mca}$, tendo emissores espaçados de 0,10 m entre si.

Os dados climáticos relativos ao período de estudo foram obtidos junto à Estação Climatológica instalada no Campus da UFLA.

Para iniciar a irrigação, determinou-se a umidade do solo até a profundidade de $0,40 \mathrm{~m}$, por concentrar maior parte das raízes do cafeeiro.

A lâmina de água aplicada durante o período de junho a setembro foi definida em função da evapotranspiração acumulada. O cálculo da evapotranspiração foi feito com base na evaporação do tanque Classe "A", considerando-se os coeficientes do tanque $K_{t}$ e da cultura $\mathrm{K}_{\mathrm{c}}$ e a precipitação ocorrida no período, conforme a Equação 1.

$$
V=\left(\left(\left(\sum E C A\right) \times K_{t} \times K_{c}\right)-P\right) \times A>
$$

em que:

$\mathrm{V}=$ volume de água a ser aplicado, em litros;

ECA = evaporação do tanque Classe "A" no período, em mm;

$\mathrm{P}$ = precipitação ocorrida no período, em mm;

$\mathrm{K}_{\mathrm{t}}=$ coeficiente do tanque;

$\mathrm{K}_{\mathrm{c}}=$ coeficiente da cultura;

$\mathrm{A}=$ área útil entre plantas, $2,8 \mathrm{~m}^{2}$;

$\mathrm{F}=$ fator de proporção de área molhada, 0,5.

O tempo de irrigação (T) foi calculado pela

Equação 2.

$$
T=\frac{V}{n \cdot q}
$$

em que:

$\mathrm{T}$ = tempo necessário de irrigação, em h;

$\mathrm{V}=$ volume de água a ser aplicado, em L;

$\mathrm{n}$ = número de emissores por planta;

$\mathrm{q}$ = vazão do emissor, $0,4 \mathrm{~L} \mathrm{~h}^{-1}$.

Entre os meses de outubro a março, embora seja o período em que ocorre maior emissão de ramos vegetativos, além de ocorrer o enchimento dos grãos, as irrigações restringiram-se apenas às lâminas aplicadas durante a fertirrigação, e/ou uma aplicação de emergência. Isso porque, na região de Lavras, as precipitações concentram-se nesse período. 


\section{Adubação}

As doses de nutrientes foram calculadas com base na análise química do solo (Tabela 1) e nas Recomendações para o Uso de Corretivos e Fertilizantes para o Estado de Minas Gerais.

Para atender às necessidades nutricionais da planta, utilizaram-se duas fontes de fertilizantes. A primeira, um adubo de alta solubilidade que contém em sua formulação $14,5 \%$ de $\mathrm{N} ; 5,16 \%$ de $\mathrm{P}_{2} \mathrm{O}_{5}$; $32,67 \%$ de $\mathrm{K}_{2} \mathrm{O}$ e também pequenas porcentagens de micronutrientes. A segunda fonte utilizada foi um nitrato de cálcio especial, também de alta solubilidade, contendo $15,9 \%$ de $\mathrm{N}$ e $13,1 \%$ de $\mathrm{CaO}$. As doses aplicadas são apresentadas na Tabela 2.

Para a aplicação de fertilizantes, utilizaram-se duas bombas hidráulicas injetoras de fertilizantes. Nas safras 1997/98 e 1998/99, utilizou-se uma bomba com taxa de injeção da ordem de $2 \%$ da vazão do sistema de irrigação. Já na safra 1999/2000, usou-se uma bomba injetora operando com uma maior taxa de injeção da ordem de $72 \mathrm{~L} / \mathrm{h}$.

A colheita foi realizada manualmente entre os meses de maio e junho, separando-se o café de pano do café de chão e, a partir do somatório desses obteve-se a produtividade total. A secagem foi feita em terreiro com monitoramento constante da umidade dos grãos, os quais foram descascados quando essa situava-se em torno de $12 \%$.

\section{RESULTADOS E DISCUSSÃO}

\section{Clima e lâminas aplicadas}

Nos meses de junho a setembro, a evaporação do tanque classe "A" (ECA) superou a precipitação, em todos os anos agrícolas estudados. Com isso, verificou-se um déficit de aproximadamente $300 \mathrm{~mm}$ superior ao déficit crítico proposto por Santinato et al. (1996); logo, pode-se, com base nessas constatações, justificar as épocas de irrigação estudadas neste trabalho.

Com exceção das precipitações, nos anos agrícolas 97/98, 98/99 e 99/00, não existiram condições climáticas prejudiciais à cultura (Umidade Relativa $<60 \%$ e Temperaturas $<14^{\circ} \mathrm{C}$ ).

Houve pouca variação entre as lâminas aplicadas via irrigação, nos diferentes anos agrícolas, para uma mesma época de irrigação. Esse fato é explicado em virtude da pequena variação climática entre os anos agrícolas. A lâmina usada para a fertirrigação no agrícola 99/00 foi significativamente inferior à lâmina aplicada nos demais anos agrícolas, em decorrência da troca do sistema de injeção de fertilizante.

TABELA 1 - Análise química do solo no início do experimento e após a safra 1999/2000. UFLA, Lavras - MG.

\begin{tabular}{cccccccccc}
\hline \multirow{2}{*}{ Data } & Fósforo & Potássio & Cálcio & Magnésio Alumínio & $\mathbf{p H}$ & $\mathbf{t}$ & $\mathbf{m}$ & $\mathbf{V}$ \\
\cline { 2 - 9 } & $\mathbf{m g} / \mathbf{d m}^{\mathbf{3}}$ & $\mathbf{m g} / \mathbf{d m}^{\mathbf{3}}$ & $\mathbf{c m o l c} / \mathbf{d m}^{3}$ & $\mathbf{c m o l c} / \mathbf{d m}^{3}$ & $\mathbf{c m o l c} / \mathbf{d m}^{\mathbf{3}}$ & & $\mathbf{c m o l c} / \mathbf{d m}^{3}$ & $\mathbf{\%}$ & $\mathbf{\%}$ \\
\hline jun/97 & 9,97 & 42,90 & 3,06 & 1,05 & 0,28 & 5,20 & 4,56 & 8,03 & 39,83 \\
ago/00 & 16,43 & 207,93 & 3,90 & 0,80 & 0,12 & 5,50 & 7,22 & 2,18 & 53,45 \\
\hline
\end{tabular}

TABELA 2 - Doses de nutrientes (g/planta) aplicadas nas três safras estudadas. UFLA, Lavras - MG.

\begin{tabular}{cccc}
\hline Safras & $\mathbf{N}$ & $\mathbf{P}_{2} \mathbf{O}_{\mathbf{5}}$ & $\mathbf{K}_{\mathbf{2}} \mathbf{O}$ \\
\hline $97 / 98$ & 70,00 & 20,00 & 135,00 \\
$98 / 99$ & 191,25 & 41,25 & 247,50 \\
$99 / 00$ & 140,00 & 25,00 & 110,00 \\
\hline
\end{tabular}




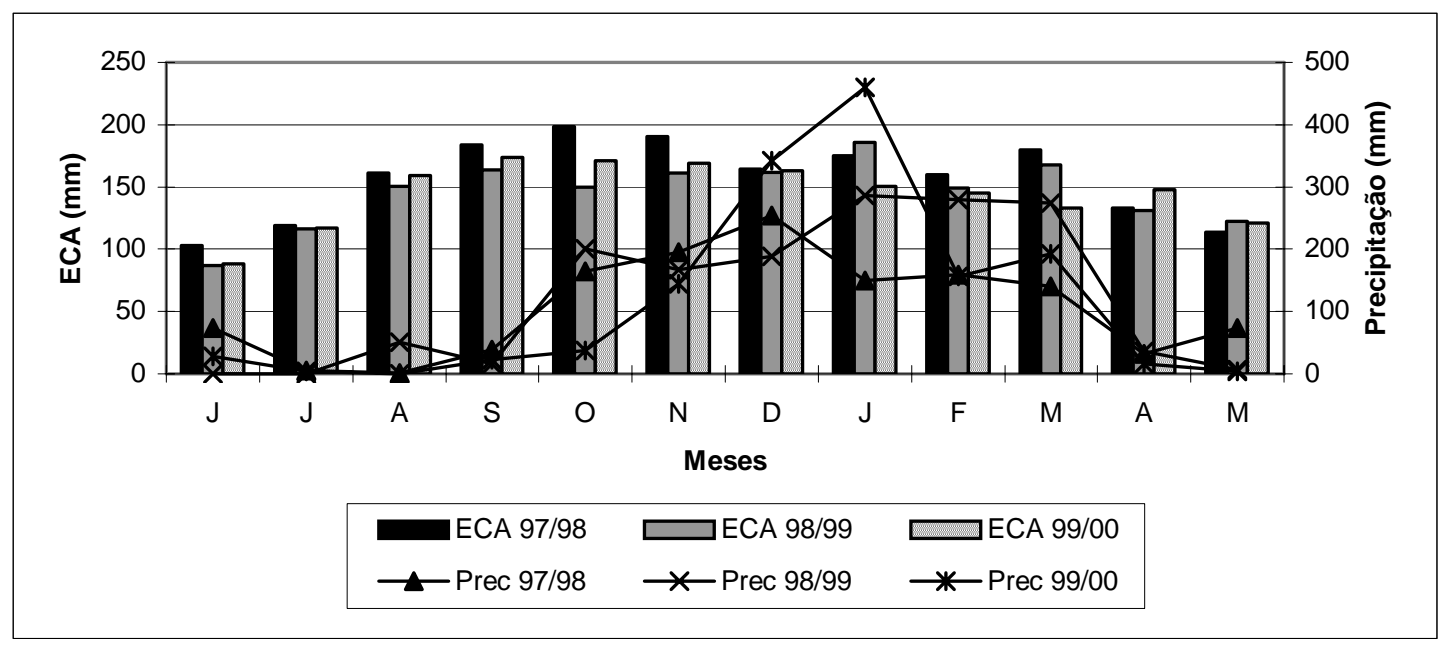

FIGURA 1 - Totais mensais de evaporação do tanque classe “A” (ECA, mm) e de precipitação (Prec, mm), para os anos agrícolas 97/98, 98/99 e 99/00. UFLA, Lavras, MG.

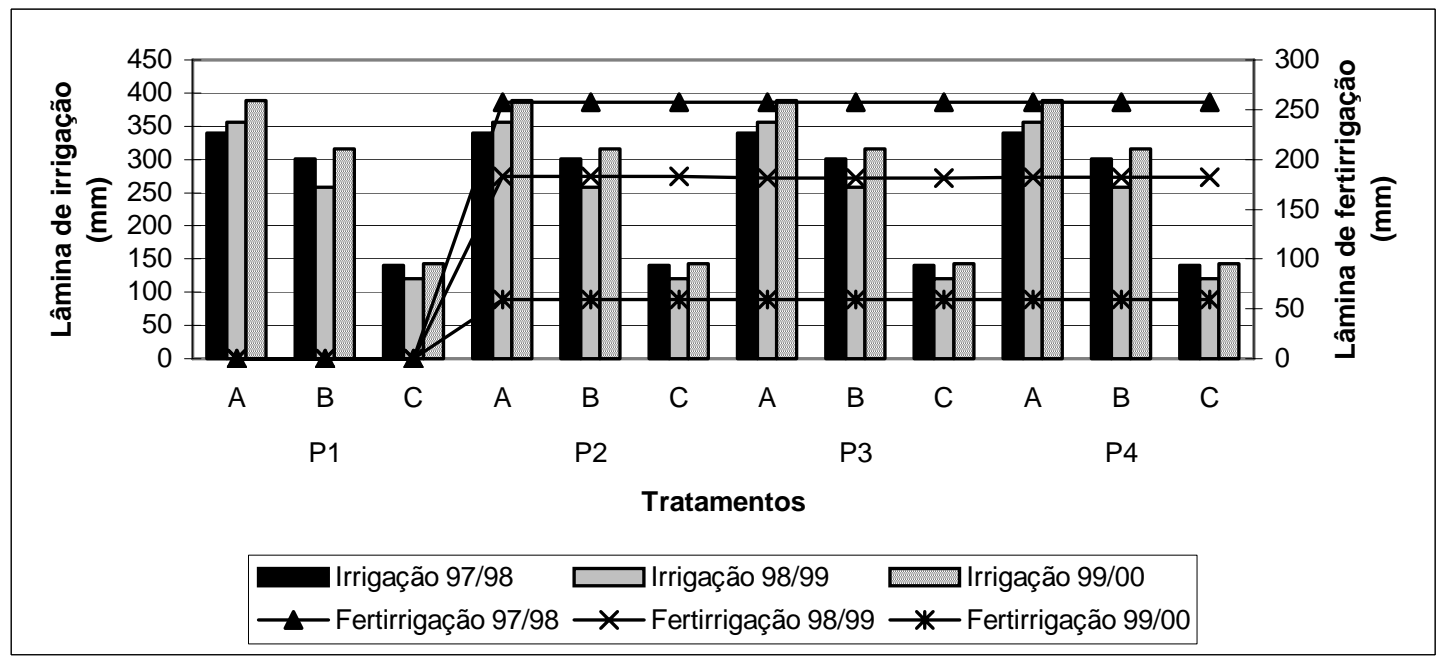

FIGURA 2 - Lâminas aplicadas, via irrigação e fertirrigação, para os anos agrícolas 97/98, 98/99 e 99/00. UFLA, Lavras, MG.

Verificou-se diferença estatística $(\alpha<5 \%)$ de parcelamentos de adubação para a produtividade de café de pano. Épocas de irrigação e safras apresentaram diferenças significativas $(\alpha<1 \%)$ em todos os parâmetros estudados. A interação entre safras e parcelamentos de adubação só foi significativa $(\alpha<5 \%)$ para o parâmetro produtividade de café do chão. A interação entre safras e épocas de irrigação apresentou efeito significativo $(\alpha<1 \%)$ pela análise de variância para os três parâmetros estudados e a interação entre safras, parcelamentos de adubação e épocas de irrigação não apresentaram diferença estatística significativa (Tabela 3).

A interação significativa entre safras e épocas de irrigação é atribuída ao ciclo bienal de produtividade, pois, provavelmente a média geral de produtividade dos tratamentos irrigados foi maior em determinada safra do que nas outras safras.

O tratamento que recebeu 12 aplicações manuais de fertilizantes propiciou a melhor produtividade (3120 $\mathrm{kg} \mathrm{ha}^{-1}$ ), sem ocorrer diferença entre os demais tratamentos (Tabela 4). 
TABELA 3 - Resumo da análise de variância contendo a soma de quadrados para a variação temporal da produtividade de pano, de chão e produtividade total, das safras 1997/98, 1998/99 e 1999/2000. UFLA, Lavras, MG.

\begin{tabular}{|c|c|c|c|c|}
\hline FV & GL & PANO & CHÃO & TOTAL \\
\hline Blocos & 2 & $498,02^{\mathrm{ns}}$ & $0,86^{\mathrm{ns}}$ & $468,11^{\mathrm{ns}}$ \\
\hline Parcelamento de adubação & 3 & $1.856,40^{*}$ & $29,86^{\text {ns }}$ & $1.818,17^{\mathrm{ns}}$ \\
\hline Resíduo (1) & 6 & 570,22 & 52,25 & 841,46 \\
\hline Épocas de irrigação & 3 & $22.188,17^{* *}$ & $466,65^{* *}$ & $28.856,20$ ** \\
\hline Resíduo (2) & 6 & 389,99 & 79,47 & 760,72 \\
\hline Parcelamento x Épocas & 9 & $3.198,37^{\text {ns }}$ & $73,16^{\mathrm{ns}}$ & $3.966,20^{\mathrm{ns}}$ \\
\hline Resíduo (3) & 18 & $3.080,60$ & 77,78 & $3.545,44$ \\
\hline Safras & 2 & $8.592,15^{* *}$ & $305,67^{* * *}$ & $8.467,63^{* * *}$ \\
\hline Resíduo (4) & 4 & 930,13 & 44,71 & $1.141,90$ \\
\hline Safras x Parcela. & 6 & $3.794,68^{\mathrm{ns}}$ & $102,22^{*}$ & $5.070,16^{\mathrm{ns}}$ \\
\hline Resíduo (5) & 12 & $3.190,50$ & 56,57 & $3.547,82$ \\
\hline Safras x Épocas & 6 & $35.920,41^{* *}$ & $350,05^{* *}$ & $43.148,97^{* *}$ \\
\hline Resíduo (6) & 12 & $3.609,91$ & 67,60 & $3.877,69$ \\
\hline Safras x Parcela. x Épocas & 18 & $5.037,38^{\mathrm{ns}}$ & $147,60^{\mathrm{ns}}$ & $5.699,64^{\mathrm{ns}}$ \\
\hline Resíduo (7) & 36 & $6.570,91$ & 175,91 & $7.778,46$ \\
\hline Total & 143 & $99.427,14$ & $2.030,36$ & $118.988,59$ \\
\hline CV 1 (\%) & & 21,12 & 45,36 & 22,49 \\
\hline CV 2 (\%) & & 17,47 & 55,94 & 21,38 \\
\hline CV 3 (\%) & & 28,34 & 31,95 & 26,65 \\
\hline CV 4 (\%) & & 33,04 & 51,39 & 32,09 \\
\hline CV 5 (\%) & & 35,33 & 33,37 & 32,65 \\
\hline CV 6 (\%) & & 37,58 & 36,48 & 34,14 \\
\hline CV 7 (\%) & & 29,27 & 33,98 & 27,91 \\
\hline
\end{tabular}

${ }^{\mathrm{ns}}$ Não significativo; ${ }^{*}$ Significativo a 5\%; ${ }^{* *}$ Significativo a $1 \%$.

TABELA 4 - Teste de comparação de médias (Tukey) para a produtividade média de café de pano das safras 97/98, 98/99 e 99/00, para os tratamentos que receberam parcelamento de adubação. UFLA, Lavras - MG.

\begin{tabular}{lcccc}
\hline Tratamentos & P1 & P2 & P3 & P4 \\
\hline Produtividade $\left(\mathrm{kg} \mathrm{ha}^{-1}\right)$ & $3120 \mathrm{a}$ & $2616 \mathrm{~b}$ & $2574 \mathrm{~b}$ & $2772 \mathrm{~b}$ \\
\hline
\end{tabular}

Valores acompanhados de mesma letra não diferem estatisticamente. 
Na safra 1998/99, obtiveram-se os melhores resultados para a produtividade de café de pano e produtividade total, com, respectivamente, 3414 e $3810 \mathrm{~kg} \mathrm{ha}^{-1}$ (Tabela 5).

Com esses resultados, confirma-se que a irrigação não elimina o efeito e do ciclo bienal de produtividade do cafeeiro, conforme o exposto por Weill et al. (2000), em ensaio com a variedade Mundo Novo, conduzido em Pindorama - SP.

Na Tabela 6 apresenta-se a análise de variância com o desdobramento das safras dentro de épocas de irrigação. Não houve efeito significativo para o parâmetro produtividade de café de chão no desdobramento de safras dentro da subparcela B (irrigada a partir de 15/08).

O teste de comparação de médias para o desdobramento de safras dentro de épocas de irrigação encontra-se na Tabela 7. Verifica-se que a irrigação não elimina o ciclo bienal de produtividade do cafeeiro, comprovado pela diferença estatística entre as médias dos diferentes tratamentos. Contudo, pode-se dizer que irrigando a partir de 01/06 e 15/07 (subparcelas A e B), há redução na amplitude de variação da produtividade entre as safras.

A produtividade total média das três safras apresentada pela subparcela A (irrigada a partir de 01/06) foi a mais alta: $4494 \mathrm{~kg} \mathrm{ha}^{-1}$. Ela foi superior àquelas apresentadas por Santinato (2001) em dois ensaios com cafeicultura irrigada: $1^{0}$ ensaio: Catuaí, na região de Bonfinópolis, MG, avaliado no período de 1993 a 1999, espaçado de 4,0 x 0,8 m, com irrigação o ano todo e aplicando $100 \%$ da evaporação do tanque Classe "A" (ECA), que apresentou uma média de produtividade de $61,6 \mathrm{sc} \mathrm{ha}^{-1}$, com a aplicação de adubo granulado diretamente ao solo; $2^{\underline{0}}$ ensaio: Mundo Novo, na região de Planaltina, GO, avaliado no período de 1994 a 1999, espaçado de 4,2 x 0,8 m, irrigado de abril a setembro, com média de produtividade de 38,0 sc ha-1.

TABELA 5 - Teste de comparação de médias (método de Tukey) para as safras 97/98, 98/99 e 99/00. UFLA, Lavras - MG.

\begin{tabular}{cccc}
\hline Safras & Pano & Chão & Total \\
\hline $97 / 98$ & $2346 \mathrm{~b}$ & $492 \mathrm{a}$ & $2838 \mathrm{~b}$ \\
$98 / 99$ & $3414 \mathrm{a}$ & $396 \mathrm{ab}$ & $3810 \mathrm{a}$ \\
$99 / 00$ & $2550 \mathrm{~b}$ & $282 \mathrm{~b}$ & $2826 \mathrm{~b}$ \\
\hline
\end{tabular}

Valores acompanhados de mesma letra na vertical não diferem estatisticamente.

TABELA 6 - Análise de variância para o desdobramento de safras dentro de épocas de irrigação, contendo a soma de quadrados dos parâmetros produtividade no pano, no chão e total. UFLA, Lavras, MG.

\begin{tabular}{ccccc}
\hline FV & GL & Pano & Chão & Total \\
\hline Safras dentro de A & 2 & $15.899,58^{* *}$ & $139,38^{* *}$ & $17.905,16^{* *}$ \\
Safras dentro de B & 2 & $4.708,59^{* *}$ & $35,99^{\mathrm{ns}}$ & $4.936,79^{* *}$ \\
Safras dentro de C & 2 & $18.165,18^{* *}$ & $238,21^{* *}$ & $21.339,63^{* *}$ \\
Safras dentro de D & 2 & $5.739,20^{* *}$ & $242,13^{* *}$ & $7.435,02^{* *}$ \\
\hline Resíduo & 16 & $4.448,36$ & 89,77 & $4.969,37$ \\
\hline${ }^{\text {ns }}$ Não significativo; &
\end{tabular}


TABELA 7 - Teste de comparação de médias (método de Tukey) para o desdobramento de safras dentro das épocas de irrigação, para a produtividade no pano, no chão e total . UFLA, Lavras, MG.

\begin{tabular}{|c|c|c|c|c|}
\hline & \multicolumn{4}{|c|}{ Subparcelas } \\
\hline & A & B & C & D \\
\hline Safras & \multicolumn{4}{|c|}{ Produtividade no Pano } \\
\hline $1997 / 98$ & $3396 \mathrm{~b}$ & $2382 \mathrm{~b}$ & $1644 \mathrm{~b}$ & $1962 \mathrm{~b}$ \\
\hline 1998/99 & $2712 b$ & 3888 a & 4014 a & 3042 a \\
\hline 1999/00 & 5664 a & 2496 b & 834 b & $834 \mathrm{~b}$ \\
\hline Média & 3924 A & 2922 B & $2164 \mathrm{C}$ & 1946 C \\
\hline CV (\%) & 32,13 & 23,48 & 62,32 & 46,28 \\
\hline Safras & \multicolumn{4}{|c|}{ Produtividade no Chão } \\
\hline 1997/98 & 666 a & 426 a & 438 a & 450 a \\
\hline 1998/99 & $408 \mathrm{~b}$ & 390 a & $444 \mathrm{a}$ & 342 a \\
\hline 1999/00 & 648 a & 282 a & $114 \mathrm{~b}$ & $78 \mathrm{~b}$ \\
\hline Média & $574 \mathrm{~A}$ & 366 B & 332 B & $290 \mathrm{~B}$ \\
\hline CV (\%) & 20,66 & 16,43 & 46,30 & 53,57 \\
\hline Safras & \multicolumn{4}{|c|}{ Produtividade Total } \\
\hline $1997 / 98$ & $4062 \mathrm{~b}$ & $2802 \mathrm{~b}$ & 2082 b & 2412 a \\
\hline 1998/99 & $3114 b$ & 4284 a & 4458 a & 3384 a \\
\hline 1999/00 & 6306 a & $2778 \mathrm{~b}$ & 954 c & $1278 \mathrm{~b}$ \\
\hline Média & $4494 \mathrm{~A}$ & 3288 B & $2498 \mathrm{C}$ & $2358 \mathrm{C}$ \\
\hline CV (\%) & 29,77 & 21,37 & 58,50 & 36,58 \\
\hline
\end{tabular}

Valores acompanhados de mesma letra não diferem estatisticamente, letras minúsculas são comparadas verticalmente e letras maiúsculas são comparadas horizontalmente.

\section{CONCLUSÕES}

A irrigação a partir de 01/06 apresentou a melhor média de produtividade e pequena variação entre safras.

A irrigação não eliminou o efeito do ciclo bienal da produtividade da cultura, mas concorreu para a sua redução.

O parcelamento da adubação em 12 aplicações manuais proporcionou a melhor média de produtividade de café de pano, já considerando a produtividade de café de chão e a produtividade total; o número de aplicações de fertilizantes e/ou a forma de aplicá-lo não provocou alterações significativas na produtividade.

\section{REFERÊNCIAS BIBLIOGRÁFICAS}

ANTUNES, R. C. B.; MANTOVANI, E. C.; SOARES, A. R.; RENA, A. B.; BONOMO, R. Área de observação e pesquisa em cafeicultura irrigada na região das vertentes de Minas Gerias: resultados de 1998/2000. In: SIMPÓSIO DE PESQUISA DOS CAFÉS DO BRASIL, 1., 2000, Poços de Caldas. Resumos Expandidos... Brasília: EMBRAPA Café; Minasplan, 2000. v. 2, p. 823826.

ANUÁRIO estatístico do café. Rio de Janeiro: Coffee Business, 2001. 161 p. 
FARIA, M. A. de; VILELLA, W. M. da C.; SILVA, M. de L. O. e; GUIMARÃES, P. T. G.; SILVA, E. L. da; OLIVEIRA, L. A. M.; SILVA, A. L. da. Influência das lâminas de irrigação e da fertirrigação na produtividade do cafeeiro (Coffea arabica L.): $2^{\mathrm{a}}$ colheita. In: SIMPÓSIO BRASILEIRO DE PESQUISA EM CAFEICULTURA IRRIGADA, 4., 2001, Araguari. Anais... Uberlândia: UFU/DEAGRO, 2001. p. 11-14.

FERNANDES, A. L. T.; SANTINATO, R.; DRUMOND, L. C. D.; LESSI, R. Irrigação e utilização de granulados de solo na produção do cafeeiro. In: SIMPÓSIO DE PESQUISA DOS CAFÉS DO BRASIL, 9., 2000, Poços de Caldas, MG. Resumos Expandidos... Brasília: EMBRAPA Café; Minasplan, 2000. v. 2, p. 957-959.

SANTINATO, R. Avanços da tecnologia de irrigação na cultura do café. In: SIMPÓSIO BRASILEIRO DE PESQUISA EM CAFEICULTURA IRRIGADA, 3., 2000, Araguari. Palestras... Uberlândia: UFU/DEAGRO, 2001. v. 1, p. 79-92.
SANTINATO, R.; FERNANDES, A. L. T.; FERNANDES, D. R. Irrigação na cultura do café. Campinas: Arbore, 1996. 146 p.

SOARES, A. R.; MANTOVANI, E. C.; RENA, A. B.; SOARES, A. A.; BONOMO, R. Produtividade do cafeeiro fertirrigado com fontes de nitrogênio e potássio na região de Viçosa, MG. In: SIMPÓSIO BRASILEIRO DE PESQUISA EM CAFEICULTURA IRRIGADA, 4., 2001, Araguari. Anais... Viçosa: UFV, 2001. p. 8489. (Boletim técnico, v. 1).

SORICE, L. S. D. Irrigação e fertirrigação de cafeeiros em produção. 1999. 59 f. Dissertação (Mestrado em Engenharia Agrícola) - Universidade Federal de Lavras, Lavras, 1999.

WEILL, M. de A. M.; IAFFE, A.; ARRUDA, F. B.; SAKAI, E.; GRANJA, N. Variabilidade da produção de café em um ensaio em Pindorama, SP. In: SIMPÓSIO DE PESQUISA DOS CAFÉS DO BRASIL, 9., 2000, Poços de Caldas-MG. Resumos Expandidos... Brasília: EMBRAPA Café; Minasplan, 2000. v. 2, p. 779-781. 